\title{
GENETIC DIFFERENTIATION IN FOUR EUROPEAN SUBSPECIES OF RED DEER (CERVUS ELAPHUS L.)
}

\author{
ULF GYLLENSTEN', NILS RYMAN ${ }^{1}$, CHRISTINA REUTERWALL' \\ AND PETER DRATCH ${ }^{2}$ \\ 1 Department of Genetics, University of Stockholm, S-106 91 Stockholm, Sweden \\ 2 Department of Forestry and Natural Resources, University of Edinburgh, Danwin Building, \\ The Kings Buildings, Mayfield Road, Edinburgh, EH9 3JU, Great Britain \\ Received 11.iii.83
}

\section{SUMMARY}

Red deer representing the four different European subspecies Cervus elaphus atlanticus, $C$. e. elaphus, C. e. germanicus, and C. e. scoticus were examined for allozyme variability at 35 enzyme loci. The proportion of polymorphic loci within populations $(P)$ ranged from 0 to 13.8 per cent and the average heterozygosity $(H)$ from 0 to 3.6 per cent. These estimates are within the range previously observed among mammalian species. Significant allele frequency differences were found both within and between subspecies. The mean genetic distance between subspecies $(\bar{D}=0.0164)$ was smaller than the differentiation at similar taxonomic levels among other ungulates, probably because of a shorter time since divergence. Within subspecies the genetic differences between populations were similar to those reported between populations within closely related species in the same geographic region. Cluster analysis based on genetic distances indicated a major genetic dichotomy between the British $C$. e. scoticus and the Norwegian $C$. e. atlanticus on one hand and the Swedish $C$. e. elaphus and the continental C. e. germanicus on the other.

Populations of pure $C$. e. elaphus were not found to differ genetically in any substantial way from Swedish populations of possible heterogeneous subspecific origin. An allele unique to C.e. scoticus was found in a Swedish enclosed population where imports of British deer are known to have taken place. A population established to preserve the genetic characteristics of the $C$. e. elaphus subspecies appeared to have lost 36 per cent of the electrophoretically measurable heterozygosity.

\section{INTRODUCTION}

The remarkable morphologic diversity and complex genetic relationships within the genus Cervus (Cervidae), comprising about 15 species and numerous subspecific forms, have since long been recognised by systematicists. Repeated taxonomic revisions have been presented for the genus (e.g., Lönnberg, 1906; Ahlén, 1965; Ellerman and Morrison-Scott, 1966; Lowe and Gardiner, 1974; Corbet, 1978). Several red deer subspecies native to northern Europe have previously been recognised, e.g., the Swedish nominate Cervus elaphus elaphus, the Norwegian $C$. e. atlanticus, the British C. e. scoticus, and the continental C. e. hippelaphus and C. e. germanicus. However, by analysis of cranium morphology Lowe and Gardiner (1974) could not find evidence for the existence of more than a single subspecies in northern Europe. The taxonomic treatments may diverge largely because they rely on different sets of morphological characters, sample sizes and statistical methods of analysis. Ideally the taxonomic description should reflect the evolutionary events giving rise to the present differentiation. Taxonomy based on quantitative characters suffers from several serious 
drawbacks relating both to the inability to distinguish between genetic and environmental components of variation and from difficulties in choosing an appropriate set of characters. The extent to which a taxonomic description based on quantitative morphologic characters reflects the genetic relationships between groups is not known. As stated by Corbet (1978) "... it must be emphasised that the great majority of mammalian subspecies are based upon differences in a single character and that a subspecific difference, even if it stands up to the most rigorous criteria now applied, should never be taken to represent any particular level of genetic difference in the absence of genetic data relating to the particular characters involved." When there are different opinions as to the proper taxonomic status of a group, a study of the degree of genetic differentiation and interrelationships with other groups may be a necessary prerequisite for a proper taxonomic treatment.

More than any other Cervus species the red deer has been intensively managed throughout its native range in northern Europe. Through selective culling, transfers and hybridisation, human intervention has drastically affected the natural genetic structure of the red deer. Man's interest has focused mainly on characters such as body size and antler shape and little is known of the extent to which the entire genetic profile of the managed populations has changed. Using discriminant function analysis of morphologic characters Lowe and Gardiner (1974) revealed two groups of deer in Great Britain, apparently corresponding to native and park derived populations. The need to preserve the genetic diversity within species has been emphasised by, e.g., Soulé and Wilcox (1980) and Frankel and Soulé (1981). To conserve adequately the genetic resources represented by native populations of red deer a genetic analysis of present populations is urgently needed.

In this study we present a quantitative analysis of the amount and distribution of genetic variability among four European subspecies of red deer, based on an electrophoretic survey of allozyme variability at 35 loci. First, the amount of genetic differentiation within and between the $C$. $e$. atlanticus, $C$. e. elaphus, C.e. germanicus, and C.e. scoticus subspecies is quantified and their genetic interrelationships are studied. In Sweden considerable interest has been devoted to the preservation of the genetic characteristics of the nominate subspecies C. e. elaphus, and in 1969 part of its range in southern Sweden was declared a wildlife reserve. Lately, deer populations outside the reserve have been rapidly increasing. These populations are to a large extent derived from deer park herds of unknown or possibly subspecific hybrid origin. The presently applied management program is clearly unable to prevent efficiently gene flow from surrounding populations into the reserve area. This raises the question whether such a gene flow would substantially change the genetic constitution of the nominate populations. The second purpose of the paper is to compare the amount of genetic differentiation between pure Swedish nominate populations and possible hybrid populations.

\section{MAterials AND MEthods}

Red deer tissue samples representing $C$. e. atlanticus, $C$. e. elaphus, C. e. germanicus, C. e. scoticus, and Swedish deer of possibly subspecific hybrid origin were collected from 22 localities. In total, 594 specimens were 
obtained. Information on the sampling localities, map codes, and subspecific designation of samples are given in table 1, and the geographic location of sampling sites in fig. 1. Locality (F), called Skåne unspecified, is not shown on the map as it refers to specimens from various places within the $\mathrm{A}, \mathrm{B}$,

TABLE 1

Description of collection sites, map codes $(A-X)$, and known or inferred subspecific composition at each locality (c.f. fig. 1)

\begin{tabular}{|c|c|c|c|}
\hline $\begin{array}{l}\text { Map } \\
\text { code }\end{array}$ & Collection site & Country & Subspecies \\
\hline A & $\begin{array}{l}\text { Red Deer Reserve } \\
\text { (Vomb, Bellinga, Krageholm, Sövde) }\end{array}$ & Sweden & C. e. elaphus \\
\hline B & Christinehof & Sweden & C. e. elaphus \\
\hline $\mathrm{C}$ & Hunneberg & Sweden & C. e. elaphus \\
\hline D & Skåne Deer Park & Sweden & C. e. elaphus \\
\hline $\mathrm{E}$ & $\begin{array}{l}\text { Skåne Deer Park } \\
\text { (central enclosure) }\end{array}$ & Sweden & C. e. elaphus \\
\hline $\mathrm{F}$ & Skåne, unspecified & Sweden & C. e. elaphus \\
\hline G & Öster-Malma & Sweden & C. e. elaphus \\
\hline $\mathrm{H}$ & Ankarsrum & Sweden & Possibly mixed \\
\hline I & Eriksberg (enclosure) & Sweden & origin \\
\hline $\mathrm{J}$ & Kolmården (free ranging) & Sweden & (C. e. elaphus \\
\hline $\mathbf{K}$ & Kolmården (enclosure) & Sweden & and possibly \\
\hline $\mathrm{L}$ & Enköping & Sweden & other north \\
\hline M & Västerås & Sweden & European subspecies) \\
\hline $\mathbf{N}$ & Hitra (island population) & Norway & C. e. atlanticus \\
\hline O & Sot Trøndelag & Norway & C. e. atlanticus \\
\hline $\mathbf{P}$ & Rhum (island population) & Great Britain & C. e. scoticus \\
\hline $\mathbf{R}$ & Ross-shire & Great Britain & C. e. scoticus \\
\hline $\mathbf{S}$ & Caithness & Great Britain & C. e. scoticus \\
\hline $\mathrm{T}$ & Loch Loggan & Great Britain & C. e. scoticus \\
\hline $\mathrm{U}$ & Strathmashie & Great Britain & C. e. scoticus \\
\hline $\mathrm{V}$ & Perthshire & Great Britain & C. e. scoticus \\
\hline $\mathrm{x}$ & Nationalpark Bayerische Wald & West Germany & C. e. germanicus \\
\hline
\end{tabular}

$\mathrm{D}$, and $\mathrm{E}$ area. All samples are from free ranging populations except those from Eriksberg (I), Kolmården (K), and Skåne Deer Park (D, E) which were collected from enclosed populations. Two of the localities $(\mathrm{N}, \mathrm{P})$ are islands. Some of the Swedish samples $(\mathrm{H}-\mathrm{M})$ were collected from localities with deer populations possibly containing genes of other subspecies, e.g., C. e. hippelaphus, C. e. germanicus, or C. e. scoticus. Several of the Swedish locations have recently (last century) been repopulated and current populations frequently represent descendants from a small number of founder individuals. For instance, the deer from Hunneberg $(C)$ are all descendants from three animals transferred from the Red Deer Reserve (A), and the population at Ankarsrum $(\mathrm{H})$ is also derived from three specimen only (Ekman, 1979).

Samples of serum, kidney, and striated muscle were collected during 1976-1980, mainly by local hunters, and stored at $-60^{\circ} \mathrm{C}$ until the electrophoretic analysis was conducted. The tissue samples were prepared and subjected to starch gel electrophoretic analysis as described by Allendorf et al., (1977) and agarose gel electrophoresis as described by Gyllensten 


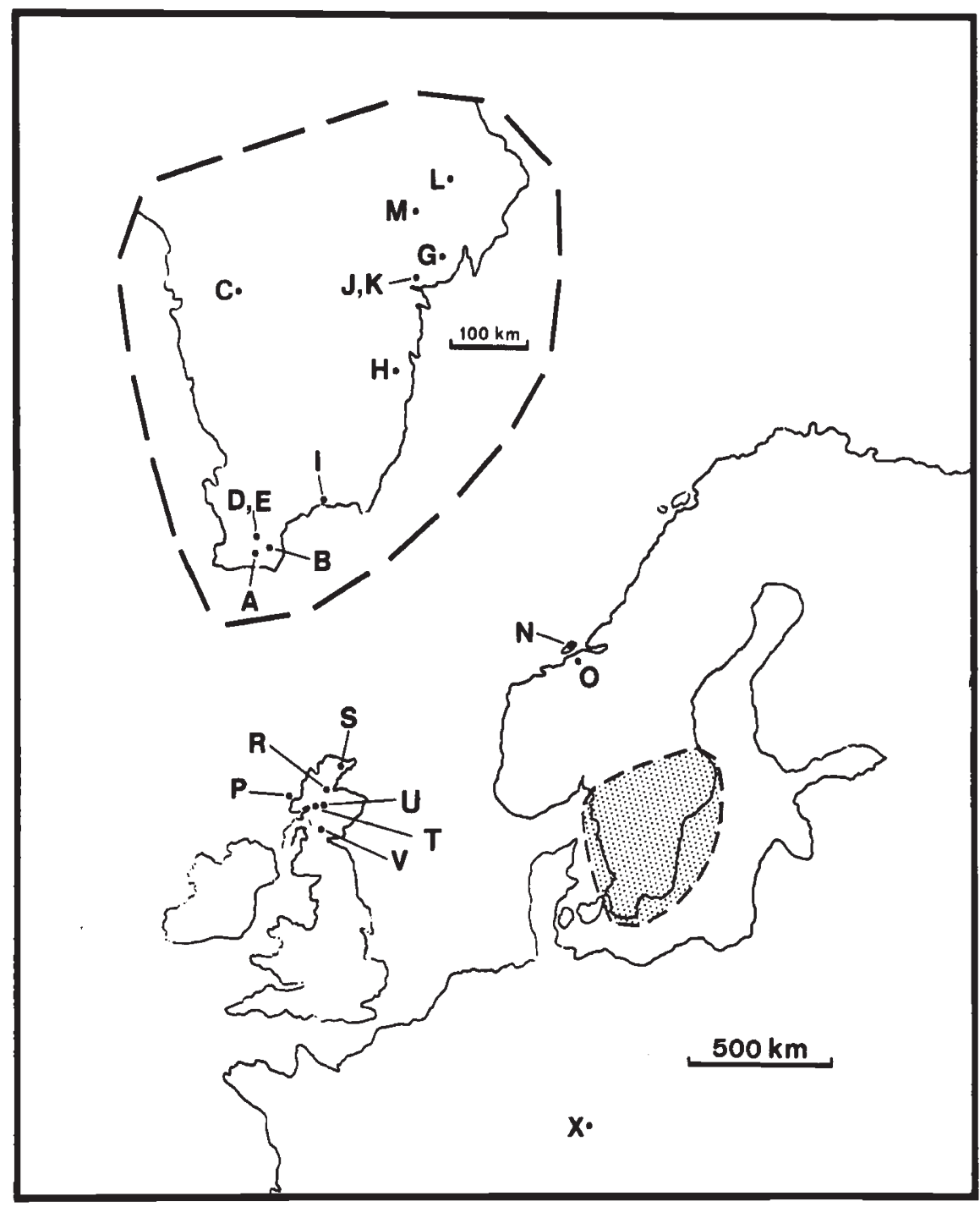

FIG. 1. The geographic location of collection sites for red deer in northern Europe. Map codes refer to table 1 . The area to the left is an enlargement of the shaded part of Sweden.

(1980) and Gyllensten et al., (1980). Four different electrophoretic buffers were used:

1. Described by Clayton and Tretiak (1972). Gel: $0 \cdot 002 \mathrm{M}$ citric acid, pH 6.0. Electrode: $0.04 \mathrm{M}$ citric acid, $p \mathrm{H} \mathrm{6 \cdot 1}$. Both the gel and the electrode buffers were $\mathrm{pH}$ adjusted with $\mathrm{N}$-(3-Aminopropyl)morpholine.

2. Described by Ridgway et al., (1970). Gel: $0 \cdot 03 \mathrm{M}$ tris, $0 \cdot 005 \mathrm{M}$ citric acid, $p \mathrm{H} 8.5$. Electrode: $0.06 \mathrm{M}$ lithium hydroxide, $0.3 \mathrm{M}$ boric acid, 
pH 8.1. Gels were made of 99 per cent gel buffer and 1 per cent electrode buffer.

3. Gel: $0.009 \mathrm{M}$ tris, $0.003 \mathrm{M}$ citric acid, $0.0013 \mathrm{M}$ ethylene-diamine tetraacetic acid, $p \mathrm{H} \mathrm{7.2}$. Electrode: $0.135 \mathrm{M}$ tris, $0.04 \mathrm{M}$ citric acid, $0.0013 \mathrm{M}$ ethylene-diamine tetraacetic acid, $\mathrm{pH} 7 \cdot 2$.

4. Described by Gyllensten et al., (1980). Gel: 0.02 M diemal Na, $0.0043 \mathrm{M}$ diemal, $\mathrm{pH} 8.6$. Electrode: tray and gel buffers were identical.

The recipes for general protein and specific enzyme stains have been adapted from Allendorf et al., (1977), Manlove et al., (1975), Harris and Hopkinson (1976), and Gyllensten et al., (1980). The following 24 proteins were examined (enzyme abbreviation, buffer system (1-4), type of tissue ( $\mathrm{M}=$ muscle, $\mathrm{K}=$ kidney, $\mathrm{S}=$ blood serum) and enzyme commission (EC) nomenclature in parenthesis): Acid phosphatase (AP, 3, M, EC 3.1.3.2), adenosine deaminase ( $\mathrm{ADA}, 1, \mathrm{M}$ and $\mathrm{K}, \mathrm{EC}$ 3.5.4.4), adenylate kinase (AK, 1, M, EC 2.7.4.3), creatine kinase (CK, 2, M, EC 2.7.3.2), esterase (EST, 2, K), glucose phosphate isomerase (GPI, 2, K, EC 5.3.1.9), $\beta$ glucuronidase (GUS, 1, K, EC 3.2.1.31), glutamate dehydrogenase (GDH, 1, K, EC 1.4.1.2), glutamate pyruvate transaminase (GPT, 2, M, EC 2.6.1.2), glyceraldehyde phosphate dehydrogenase (GAPDH, 2, M, EC 1.2.1.12), glycerol-3-phosphate dehydrogenase (GPD, 2, M, EC 1.1.1.8), hexokinase (HK, 3, K, EC 2.7.1.1), isocitrate dehydrogenase (NADP ${ }^{+}$) (IDH, 2, M, EC 1.1.1.42), lactate dehydrogenase (LDH, 2, M, EC 1.1.1.27), malate dehydrogenase (MDH, 1, M, EC 1.1.1.37), malic enzyme (ME, 2, $\mathrm{M}, \mathrm{EC}$ 1.1.1.40), mannose phosphate isomerase (MPI, 1, M, EC 5.3.1.8), peptidase (PEP, 3, K), phosphoglucomutase (PGM, 3, K, EC 2.7.5.1), phosphogluconate dehydrogenase (PGDH, 1, K, EC 1.1.1.44), pyruvate kinase (PK, 1, K, EC 2.7.1.40), sorbitol dehydrogenase (SDH, 1, K, EC 1.1.1.14), superoxide dismutase (SOD, $1, \mathrm{~K}, \mathrm{EC}$ 1.15.1.1), and transferrin (Tf, 4, S).

The different enzymes were routinely assayed by specific staining procedures, while transferrin was routinely visualised by staining with Coomassie (Gyllensten et al., 1980).

The genetic interpretation of electrophoretic patterns of a protein followed the principles outlined by Allendorf et al., (1977) with special reference to brown trout (Salmo trutta). The interpretation was based on the tissue distribution and inferred enzyme structure (Darnall and Klotz, 1975), the frequencies of different phenotypes, and comparison with the patterns observed in closely related species, e.g., the moose (Alces alces, Ryman et al., 1980a).

The nomenclature used to designate protein loci and alleles follows the system originally proposed by Allendorf and Utter (1979). An abbreviation is chosen for each protein (see above); when in italics this abbreviation denotes the locus coding for the protein. If multiple loci occur a hyphenated numeral is included, and loci are numbered starting with the least anodal form. Allelic variants are designated according to their relative electrophoretic mobility. One allele is arbitrarily designated 100 and other alleles at the locus are given numerical values representing the electrophoretic mobility of their gene products relative to this unit distance. A locus is considered polymorphic if the frequency of the most common allele does not exceed 0.99 . 


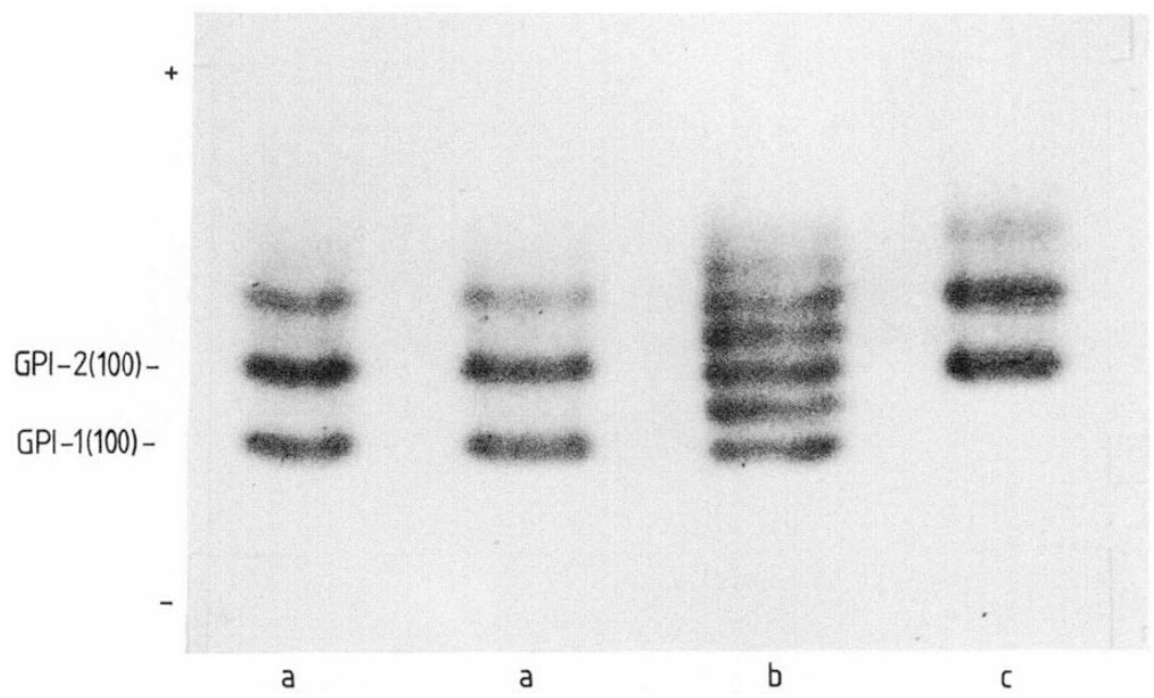

FIG. 2. The electrophoretic pattern of glucose phosphate isomerase (GPI) in red deer muscle. For each locus the position of the common allele homodimer is indicated. The different phenotypes are interpreted as: a, GPI-1(100/100); b, GPI-1(100/160); c, GPI$1(160 / 160)$. 
to code for this enzyme in man (Harris and Hopkinson, 1976). We observed variability at $S O D-1$; the phenotypes were consistent with those for a dimeric enzyme encoded by a single locus segregating for two alleles.

Blood serum permitting the scoring of $T f$ was obtained from all but the Scottish and West German localities. The identification and genetic interpretation of red deer transferrin variability patterns have been described by Gyllensten et al., (1980). Three alleles were found in Swedish populations but only one in Norwegian populations.

For the enzymes AP, CK, GAPDH, GDH, GPD, GPT, GUS, MPI, PEP, PGDH, PK, and SDH only a single locus each could be postulated, none of which showed variation. Several of these enzymes, e.g., AP, GPD, PEP, and PK have been reported to be encoded by two loci in man (Harris and Hopkinson, 1976). The inability to detect multiple forms under the present electrophoretic conditions may result from the difficulties in obtaining sufficiently fresh tissue samples. The enzymes ADA, AK, EST, HK, and $\mathrm{LDH}$ were all present in multiple forms.

The genetic interpretation of zymograms was supported by a lack of significant differences in phenotype appearance or frequency for sex or age (calf-adult) categories at any locus. Chi-square tests for deviation of observed phenotype distributions from expected binomial proportions were significant in four out of 66 cases ( 6 per cent).

\section{(ii) Amount and distribution of genetic variability}

There are two circumstances that make a clear and straightforward result presentation difficult. First, some of the Swedish samples are from populations of possibly hybrid origin. Our conclusion (see below) is that all but one (location I) of those samples represent populations with only little, if any, admixture of genes very different from the $C$. e. elaphus subspecies. It should be stressed that our intention is not to revise the taxonomy of Cervus elaphus but rather (i) to estimate the amount and distribution of electrophoretically detectable genetic variation among recognised taxonomic units in northern Europe, and (ii) to assess the amount of genetic divergence among populations in Sweden as a basis for management decisions with respect to conservation of red deer genetic resources. To accomplish the first objective we have exclusively focused on samples which can be unambiguously classified as belonging to either of the presumably "pure" subspecies. The second problem is that some of the sample sizes are so small that their inclusion in quantitative analyses may introduce a large random bias. This obstacle is particularly obvious for the only sample assumed to represent the $C$. e. germanicus subspecies (location X; nine specimens). To reduce this problem we have for the majority of presentations somewhat arbitrarily focused on populations represented by samples sized larger than ten. However, in order to provide a presentation as complete as possible, we have in some cases also given the results based on calculations performed on the total set of data.

The frequency of the most common allele (100) at variable loci is shown in table 2 together with sample sizes and estimates of average heterozygosity $(H)$. With the exception of the $M D H-2(125)$ allele, no localised subspecies unique alleles were found. Most alleles were present in several subspecies. 


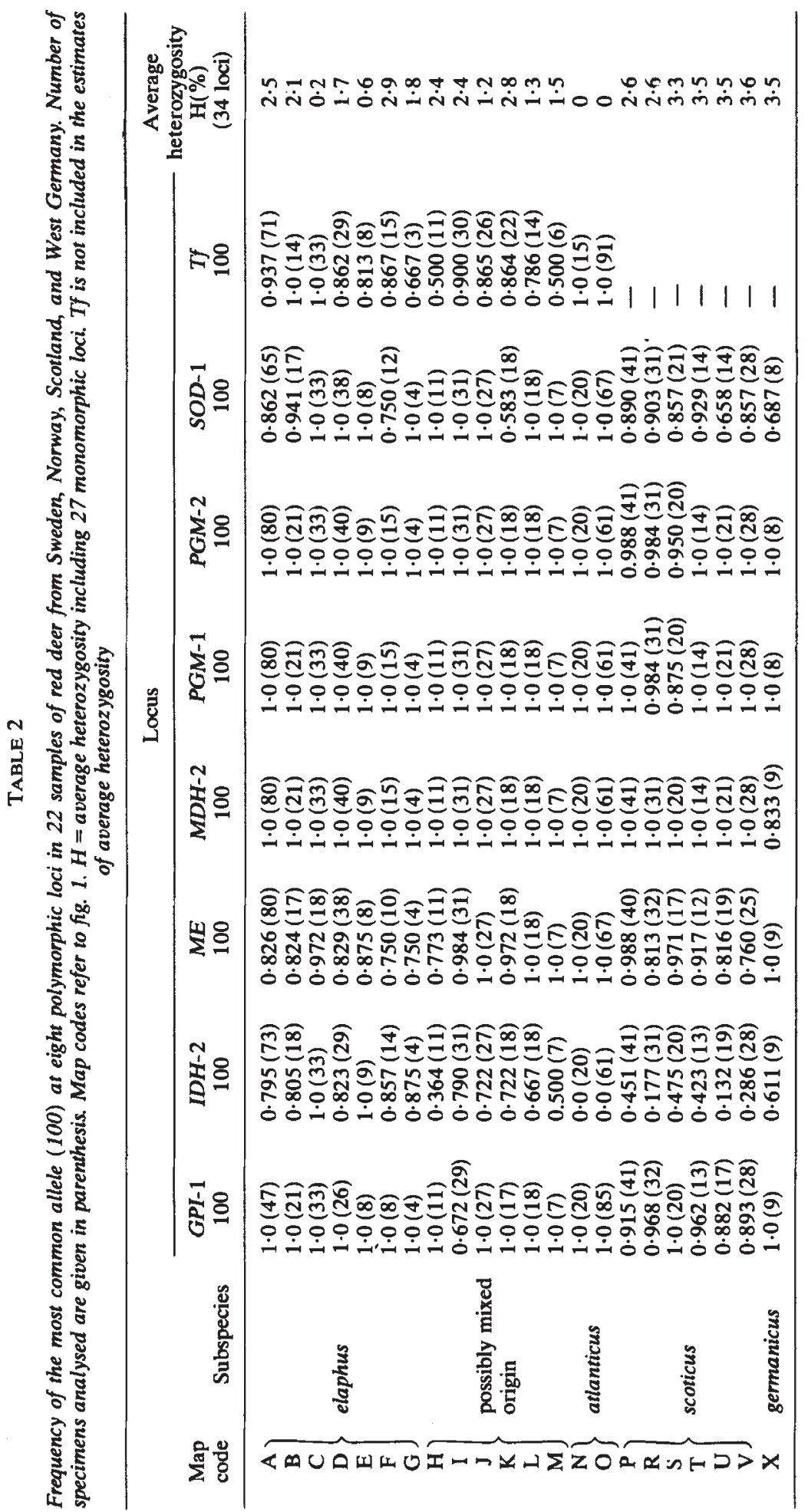


The average heterozygosity $(H)$ as well as the proportion of polymorphic loci $(P)$ was lowest in the atlanticus subspecies $(H=0$ per cent and $P=0$ per cent) and highest in the scoticus subspecies $(\bar{H}=3.0$ per cent and $\bar{P}=13.8$ per cent). In fact, the average heterozygosity of $C$. e. scoticus was significantly higher than that of other subspecies (Mann-Whitney U-test; $P<0.005$ ).

Tests for allele frequency homogeneity were performed hierarchically by a $\log$-likelihood ratio $(G)$ test (Sokal and Rohlf, 1969). Comparisons were made between localities within subspecies, between the elaphus populations (localities $A-G$ ) and those of possibly mixed origin (localities $\mathrm{H}-\mathrm{M}$ ) within Sweden, and finally among the four subspecies (table 3). Highly significant allele frequency differences were found between localities within elaphus, within scoticus, as well as within the group of Swedish localities with populations of possibly mixed origin (table 3). No differences were found between the two samples of atlanticus. Three out of four polymorphic loci showed heterogeneity in elaphus, four out of six in scoticus, and all five in the possibly mixed group. Thus, there was no consistent tendency for any particular locus to contribute more than the others to the total $G$ statistic.

Significant allele frequency heterogeneities were found between the two groups of deer within Sweden (elaphus vs possibly mixed origin) at four of the five polymorphic loci (table 3). Finally, heterogeneity between subspecies was found at all of the polymorphic loci scored in all subspecies. A large part of the overall heterogeneity was caused by the differentiation at $I D H-2$. However, the significance of the total $G$ statistic persisted also when this locus was excluded from the analysis.

Nei's (1972) genetic distance between localities was calculated from the allele frequencies at 34 loci ( $T f$ excluded). The average genetic distance $(\bar{D})$ between subspecies $(\bar{D}=0.0164$ and $\bar{D}=0.0182$ with and without germanicus, respectively) was considerably higher than that observed between populations within subspecies (table 4). The largest differentiation between locations was found within $C$. e. scoticus $(\bar{D}=0.0027)$ followed by $C$. e. elaphus $(\bar{D}=0.0014)$. Due to identical fixation at all loci in the two samples examined no differentiation was detected in C. e. atlanticus.

The amount of genetic variation attributable to different sources of variation was estimated by a hierarchical gene diversity analysis ( $\mathrm{Nei}, 1975$; Chakraborty et al., 1982). The total gene diversity was partitioned (similarly to the $G$ analysis) into the following components (table 5): between "pure" subspecies, between populations (localities) within subspecies, and within populations. Of the total gene diversity approximately 22 per cent was found between subspecies and 5 per cent between populations within subspecies, while 73 per cent was attributable to variation within populations.

\section{(iii) Genetic interrelationships between subspecies}

Cluster analysis based on genetic distances was performed using the unweighted pair group algorithm with arithmetic means (UPGMA; Sneath and Sokal, 1973). The genetic relationships ( $T f$ excluded) between samples representing the "pure" atlanticus, elaphus, and scoticus subspecies is shown in fig. 3 (excluding populations represented by less than ten specimens). 
ULF GYLLENSTEN ET AL.

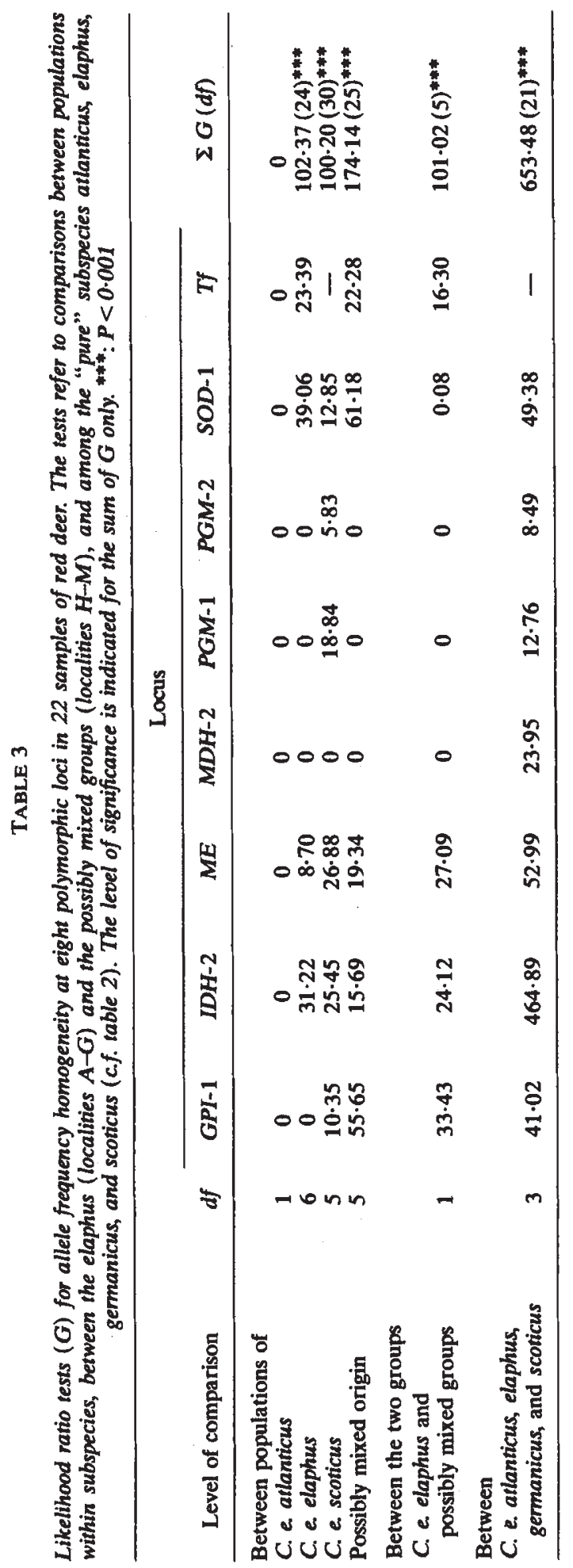




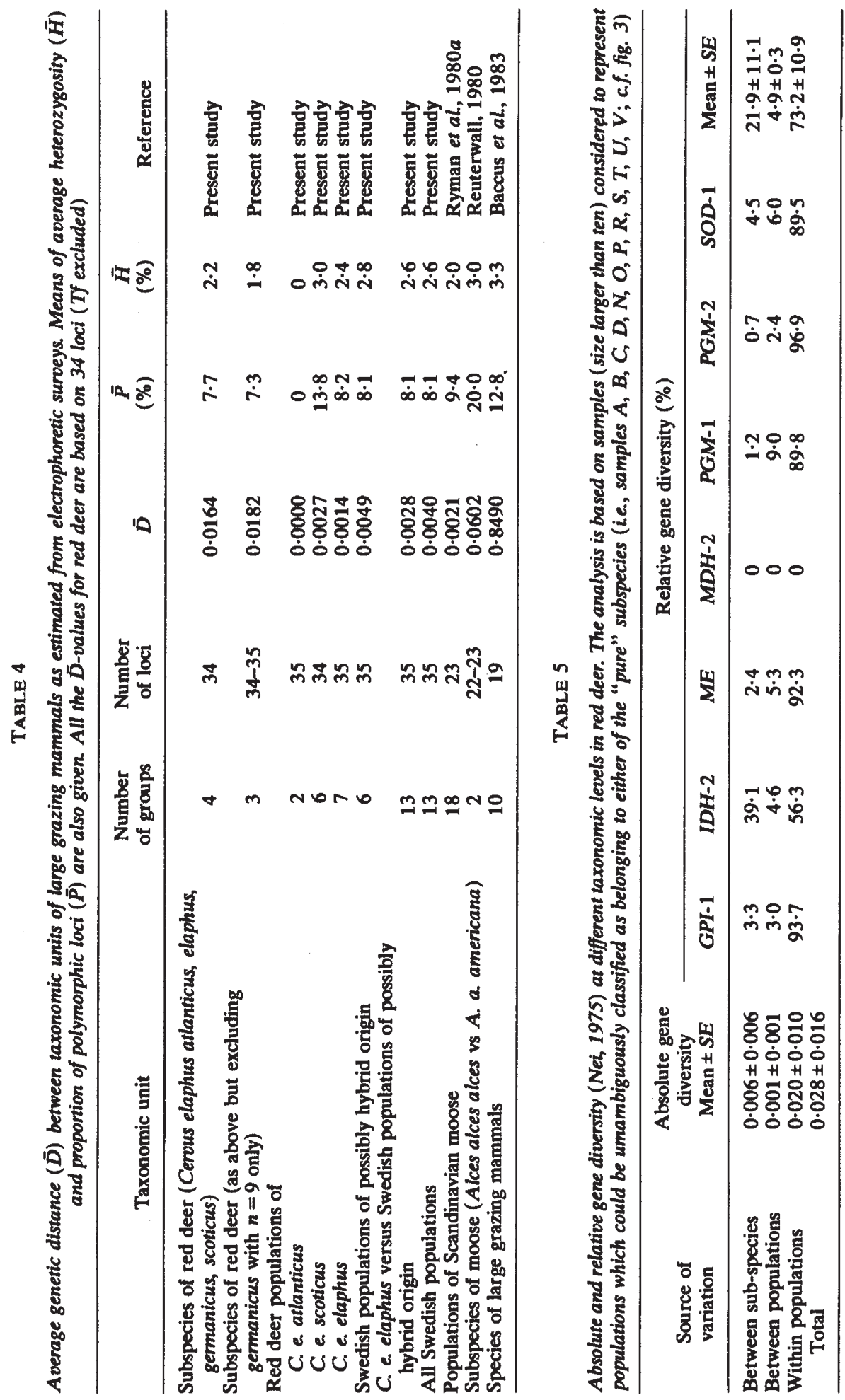




\section{GENETIC DISTANCE}

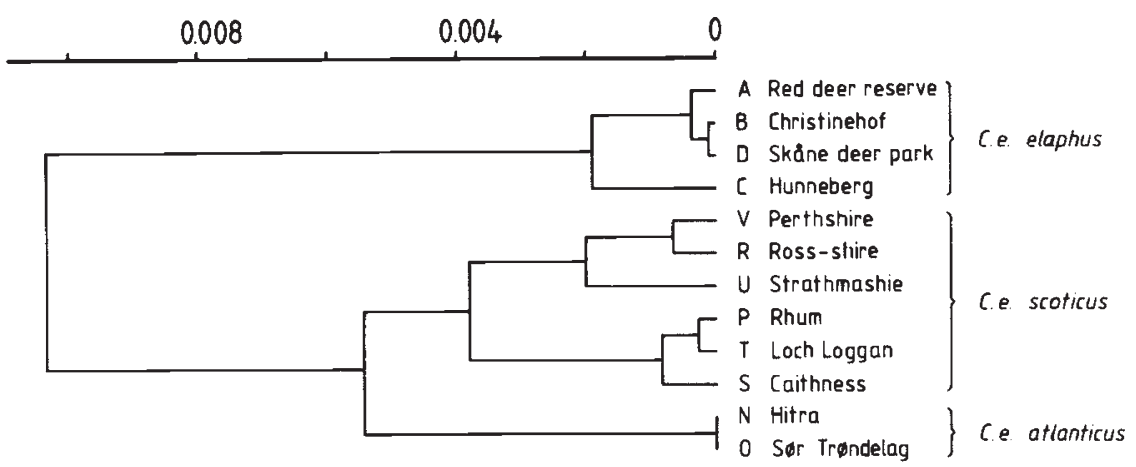

FIG. 3. The genetic relationship between samples of red deer representing "pure" $C$. $e$. atlanticus, $C$. e. elaphus, and $C$. e. scoticus. The dendrogram is constructed by the UPGMA-algorithm from Nei's genetic distance. It is based on 34 loci ( $T f$ excluded) and includes samples with more than ten specimens analysed.

The main branching point $(D \approx 0 \cdot 013)$ separates the elaphus populations from those of atlanticus and scoticus. The dendrogram indicates a higher genetic similarity between atlanticus and scoticus as compared to elaphus. The robustness of the topology of the dendrogram was tested by successive removal of single polymorphic loci before constructing the dendrogram. The removal of the $I D H$-2 locus results in a different clustering of localities. In contrast, the removal of any other locus results in minor alterations only, i.e., relocation of single samples or changes in branch length. Thus, the pattern of genetic differentiation observed among subspecies is strongly influenced by the variability pattern at a single and highly diagnostic locus (IDH-2).

The general dendrogram topology remained the same when the Swedish populations with deer of possibly hybrid origin were included (fig. 4). The small sample from germanicus appears to be more similar to elaphus than to any other subspecies.

To assess the effect of the $T f$ locus (not scored in all samples) on the pattern of subspecies differentiation the allele frequencies were pooled over localities for each of the polymorphic loci within each subspecies. Tf allele frequency estimates for the germanicus were from Bergmann (1976) and estimates for scoticus from McDougall and Lowe (1968). The Bergmann (1976) samples were compared with Swedish ones on the same gel, while the similarity between the common allele in scoticus and the 100 in elaphus and germanicus was inferred from the zymogram photographs by McDougall and Lowe (1968). The inclusion of the Tf locus did not alter the clustering of subspecies in the dendrogram. C. e. germanicus appeared more closely related to elaphus than to any of the other subspecies.

\section{(iv) Hybrid populations}

The $P$ and $H$ estimates for the Swedish samples of possibly hybrid origin were not higher than those for the elaphus subspecies (tables 2 and 4 ) as 


\section{GENETIC DISTANCE}

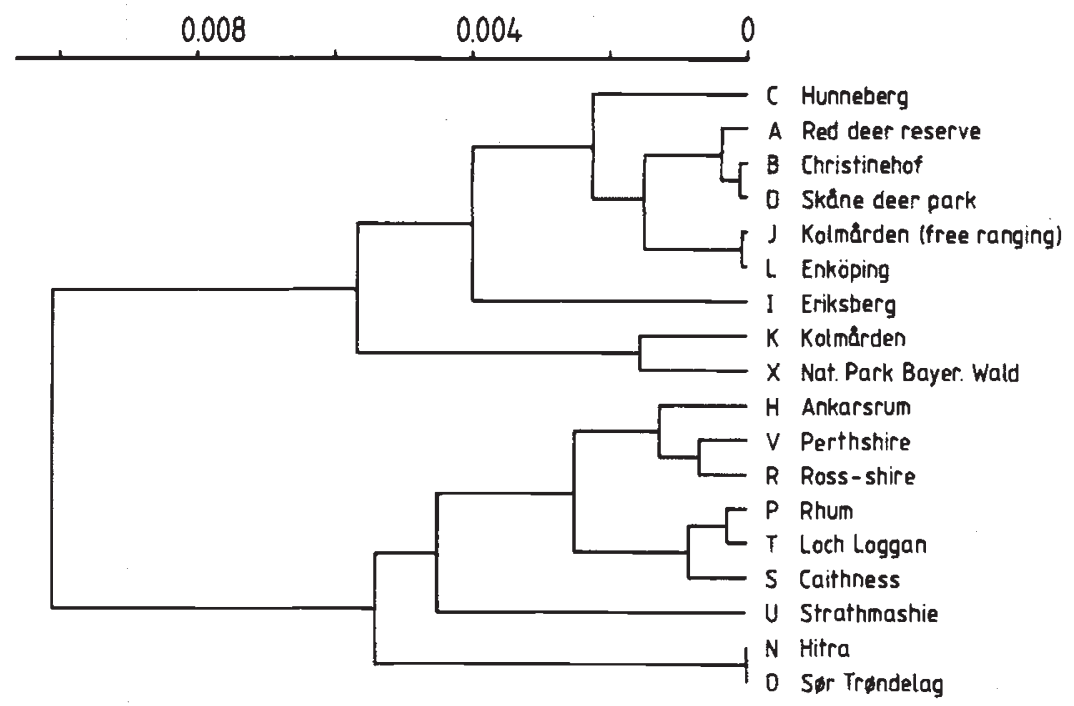

FIG. 4. The genetic relationships between all samples of red deer with more than ten specimens analysed. The only sample representing $C$. e. germanicus (location X, nine specimens) is also included. The dendrogram is based on 34 loci ( $T f$ excluded).

would have been expected if they represent recent crosses between genetically divergent subspecies. The average genetic distance between the "pure" elaphus populations was smaller than both the average genetic distance between populations of possibly mixed origin and that observed between all the Swedish populations (table 4 ). The $\bar{D}$ value between populations of the two Swedish groups $(\bar{D}=0.0028)$ was almost equivalent to that between populations of $C$. $e$. scoticus. It is obvious that the absolute amount of differentiation $(D)$ within Sweden is much smaller than that observed between subspecies. A hierarchical gene diversity analysis calculated for the Swedish samples alone indicates that the gene diversity between populations within each of the two groups of deer ("pure" elaphus versus deer of possibly mixed origin) was approximately twice (11.4 per cent) the diversity attributable to differences between the two groups ( 5.5 per cent). Except for a single location $(\mathrm{H})$ all the Swedish samples were found in the same main cluster in the dendrogram (fig. 4). The Swedish deer from Ankarsrum $(\mathrm{H})$ cluster with scoticus. The deer from the $\mathrm{H}$ locality are derived from three specimens only, and the apparent similarity to scoticus may thus reflect a founder effect rather than a true subspecific relationship.

At large, the data do not indicate the existence of genetic differences within Sweden of the magnitude observed between populations unambiguously classified as belonging to different subspecies. The only exception is represented by the deer park herd at Eriksberg (I) where an allele (GPI-1(160)) not found elsewhere in Sweden but present at several Scottish localities was identified. Recent information indicates that imports of red deer from Great Britain to this inclosure has actually taken place, and the herd at this location appears to be of hybrid origin. 


\section{Discussion}

\section{(i) Amount and distribution of genetic variability}

The amount of electrophoretically detectable genetic variability in red deer is of the same magnitude as found among other species of ungulates (table 4) and among vertebrates in general (Nevo, 1978). The suggestion (Selander and Kaufmann, 1973) that large mobile animals should be characterised by very low levels of genetic variability is not supported by our results. As pointed out by Ryman et al. (1980a) large numbers of loci, populations, and individuals may be needed to permit an adequate description of the level of variability among ungulate species.

The average genetic distance $(\bar{D}$; table 4$)$ between subspecies is considerably smaller than that observed between subspecies within closely related species, e.g., European and Canadian moose (Alces alces alces versus $A$. a. americana with $\bar{D}=0.0602$; Reuterwall, 1980) or between European reindeer and caribou (Rangifer tarandus tarandus versus $R$. $t$. caribou with $\bar{D}=0 \cdot 174$; Baccus et al., 1983). In contrast, the amount of differentiation between local populations within subspecies of red deer is of the same magnitude as that estimated for local populations of moose in Scandinavia (table 4).

Although the absolute amount of genetic divergence $(D)$ between subspecies and populations within the red deer is of the same magnitude or smaller than that observed within closely related species, a remarkably small fraction of the total gene diversity ( 73 per cent) is found within populations. The major part of the between populations component ( 27 per cent) is attributable to variation between subspecies ( 22 per cent) whereas only 5 per cent is found between local populations within subspecies. The relative amount of variation between subspecies is larger than found between major races of man (approximately 5 per cent for electrophoretic loci; Ryman et al., 1983). In contrast, the relative amount of gene diversity found between local populations within subspecies of red deer is similar to the one derived for human populations within major races (approximately 4 per cent for electrophoretic loci; Ryman et al., 1983) or local moose populations in Scandinavia (10 per cent, Ryman et al., 1980); it falls in between the very high mean for freshwater fishes and the low means observed for marine fishes (Gyllensten and Ryman, in preparation) and birds (Gyllensten, in preparation). This pattern for distribution of genetic variability is somewhat unexpected considering the social structure of the red deer (e.g., Smith, 1979). From the red deer harem breeding system we would expect a larger fraction of the total gene diversity in this species to be distributed between local populations (within subspecies) than in the moose which has a much less closed social structure. It should be stressed that the minor fraction of the total gene diversity found between local populations within subspecies of red deer does not change considerably if the atlanticus populations are excluded from the analysis. For instance, the relative diversity between local populations is 5 per cent and 7 per cent for the "pure" elaphus and scoticus populations, respectively. Our results may indicate that the genetically effective breeding structure in red deer permits more gene flow among breeding units than might be expected from the apparent breeding pattern. 


\section{(ii) Divergence between subspecies}

The analysis of cranium morphology by Lowe and Gardiner (1974) revealed a very high degree of morphologic similarity among subspecies of red deer; only the atlanticus subspecies had an overlap less than 10 per cent with other subspecies. The amount of genetic differentiation between European subspecific forms appears to be smaller than that found at comparable taxonomic levels for other ungulate species (table 5). Both the comparison with moose and reindeer include subspecies from North America which have accumulated differences for a considerably longer period of time. The genetic distance between the European red deer and the wapiti ( $\bar{D}=0.290$; Baccus et al., 1983), which is regarded as a Cervus elaphus subspecies by some taxonomists (Corbet 1978), is similar to the amount of differentiation between subspecies of moose and reindeer. This indicates that the low differentiation in European red deer is not caused by a generally slower protein divergence in Cervus, but rather by a shorter time since divergence (Avise et al., 1980). In comparison with the absolute amount of differentiation between subspecific units of other organisms, the European red deer appears to be at the lower range of values reported (Nei, 1975; Corbin, 1977). The problem in assigning subspecific names to segments of the European red deer population may thus be real; the low morphological divergence is actually reflecting a comparatively low level of absolute genetic divergence. The general variability pattern with a rather small amount of absolute divergence $(D)$ between subspecies coupled with a high fraction of the total gene diversity distributed between subspecies may indicate that founder effects and genetic drift have strongly influenced the recent evolution of the north European red deer.

The cluster analyses indicate a major genetic dichotomy between the scoticus and atlanticus subspecies on one hand and the elaphus and germanicus subspecies on the other. A common ancestor for the scoticus and atlanticus subspecies has earlier been suggested on the basis of their morphological similarity (Cameron, 1923). Lowe and Gardiner (1974) did not find support for this hypothesis. Instead they postulated a continental ancestor common to both Scandinavian and British deer. To depict the morphological relationships between subspecies the Euclidean distance matrices given by Lowe and Gardiner (1974) were used to construct dendrograms by the UPGMA algorithm (fig. 5). Both in the dendrograms from Euclidean distances based on principal component analysis and that based on canonical variate analysis the scoticus and atlanticus subspecies cluster in the same main branch, well separated from the elaphus and some samples of the hippelaphus subspecies. Thus, both the dendrograms constructed from genetic and from morphologic data indicate a generally higher similarity between atlanticus and scoticus than to elaphus and to some continental hippelaphus populations. If subspecies are to be recognised in Europe this major branching observed congruently in genetic and morphologic characters should be reflected.

From the conversion suggested by Nei (1975) the genetic distance between the two main branches in the dendrogram would correspond to an approximate divergence time of 60,000 years. However, the time available for postglacial subspeciation (4000-8000 years; Ahlén, 1965) is much shorter. Although the estimate of time since divergence based on protein 
a

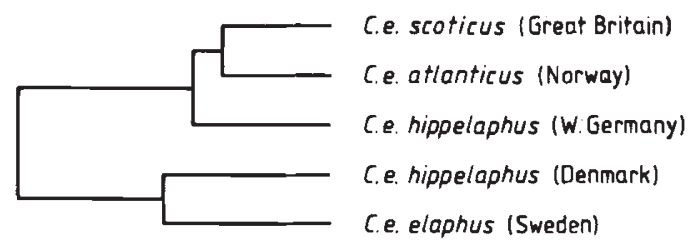

b

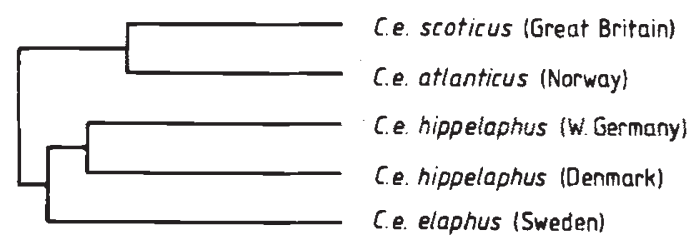

FIG. 5. Morphological relationships between subspecies. The dendrograms are constructed by the UPGMA-algorithm from the Euclidean distance matrices based on a) principal component analysis and b) canonical variate analysis given by Lowe and Gardiner (1974).

data has a large standard error and relies on a number of assumptions, it indicates that the differentiation between the two groups was initiated prior to the end of last glaciation rather than afterwards. A common origin for atlanticus and scoticus was previously explained by the assumed migration of deer from the British Isles to Norway. Those deer were supposed to have survived on glacial refuges on the Norwegian west coast. The theory of glacial refuges is under debate and the means by which migration may have occurred are not fully understood. The current similarity between atlanticus and scoticus may be explained by two alternative hypotheses. First, it may result from two subsequent invasions of red deer in northern Europe, the first one followed by an eradication of red deer from some continental areas, but with remnant populations in Norway and the British Isles. Second, we may infer selective pressures affecting the allozyme frequencies and quantitative cranial characters simultaneously. However, in the light of the large amount of data collected in other species indicating that the majority of isozyme loci behave as selectively neutral ones, we consider this explanation a less likely one (Avise, 1974; Chakraborty et al., 1980; and references therein).

\section{(iii) Management implications}

The red deer has been subjected to intensive management. Indeed, in some areas enclosed stocks may be regarded as almost semi-domesticated; their deaths, births, and migration are almost totally controlled through selective culling by man. As with many domesticated and wild species there is a strong need to assess the genetic implications of various management activities (Frankel and Soulé, 1981).

The gene diversity between the two groups of deer in Sweden is only half the amount found between populations within each group. The genetic 
distance between the groups is similar to the differences among scoticus populations or local populations of other ungulate species. In our opinion, these results do not justify general management efforts aimed at preventing gene flow between Swedish populations of pure nominate and presumed hybrid origin. It should be noted that a large part of the divergence among the populations of hybrid origin, as well as between this group and the pure elaphus populations, is due to the Eriksberg sample. The presence of the $G P I-1(160)$ allele among the enclosed deer from Eriksberg (I) indicates that foreign deer have been successfully introduced into that herd. This population should thus be isolated from surrounding nominate deer.

If the genetic resources represented by nominate allele and allelic combinations are to be preserved, it is more important to minimise the gene flow between populations from different genetic main groups (fig. 4). In particular, the gene flow from the expanding atlanticus populations should be addressed. Today Norwegian deer have just begun to enter Sweden, and a hybrid zone will be established unless this is in some way prevented.

The deer from the Hunneberg (C) nominate population have a very low level of genetic variability as compared to other nominate populations. This population was founded by three animals from the Red Deer Reserve (A) in an attempt to preserve the genetic characteristics of the nominate subspecies. When starting a population with such a small number of founders only 25 per cent of the alleles in the ancestral population are likely to be retained (Nei et al., 1975). The majority of the loss refers to alleles segregating at low frequencies, and the entire reduction is therefore not likely to be detected by means of standard electrophoretic techniques. The Hunneberg (C) population currently appears monomorphic at all but one of the loci polymorphic in the ancestral population. Further, it only exhibits 64 per cent of the electrophoretically measurable heterozygosity (table 2). Theoretically we expect to retain 83 per cent of the heterozygosity when sampling three specimens from a large population. However, small population size in subsequent generations further reduces the genetic variability (Nei et al., 1975), and the actually observed reduction of heterozygosity by 36 per cent is equivalent to the inbreeding from two generations of full sib mating $(F=0 \cdot 375)$. Such high inbreeding coefficients have been shown to be connected with the expression of deleterious genes in other species (Falconer, 1960; Kincaid, 1976). The negative effects of inbreeding have long been recognised by plant and animal breeders but it is not until recently that the short term genetic effects of inbreeding in wild species have been fully acknowledged (Ralls et al., 1979). Those studies give no support for the view that species with a social structure apparently conferring certain amounts of inbreeding, e.g., polygynous deers, should be less sensitive to close inbreeding than other species (Smith, 1979; Whitehead, 1978). Those observations are in good agreement with our present results indicating that under natural conditions the genetically effective social structure of the red deer does not necessarily promote inbreeding to such an extent than may have been anticipated previously.

It is clear that introductions into unpopulated areas should preferably be based on considerably larger numbers of effective parents than used for Hunneberg. Even if this population will survive in the short term, it will remain depauperate in allelic diversity. The long term evolutionary con- 
sequences will inevitably be a reduced potential for adaptive change (Soulé and Wilcox, 1980; Frankel and Soulé, 1981). When the aim is to preserve the genetic characteristics of a unique population the ambition should be to meet with the standards for size for founding and maintenance of populations (Frankel and Soulé, 1981). A proper management of genetic resources calls for both an identification of the units to be conserved and an increased awareness of the genetic effects of human interventions (Senner, 1980; Ryman and Ståhl, 1980; Ryman et al., 1980b).

Acknowledgements. The study was supported by grants from the National Swedish Environment Protection Board, the Swedish Natural Science Research Council, the Fulbright Commission, the C. F. Liljevalch J:r foundation, and the Elizabeth Sinclair Irvine fund. We sincerely acknowledge the contribution of Bengt Andersson, Egon Axelsson, Iens Berg, Lambart von Essen, Sven Fredga, Rolf Langvatn, Alf Lettesjö, Karl-Henry Lundin, Svein Myrberget, Per Pettersson, Karl Radler, Bengt Ole Röken, Tom Sinding-Larsen, and Bertil Österberg in collecting the samples as well as the stalkers for the forestry Commission, the Nature Conservancy Council and private estates in Scotland. We also greatly appreciate the collaboration with Dr M. H. Smith, Savannah River Ecology Laboratory, South Carolina, U.S.A. and Dr R. J. Berry, Royal Free Hospital School of Medicine, London, England in adapting the electrophoretic techniques for analysis of red deer. Drs M. H. Smith and G. Ståhl kindly reviewed a preliminary version of the manuscript.

\section{REFERENCES}

AHLÉN, I. 1965. Studies on Red deer, Cervus elaphus L., in Scandinavia. II. Taxonomy and osteology of prehistoric and recent populations. Viltrevy, 3, 89-176.

ALLENDORF. F. W. AND UTTER, F. M. 1979. Population genetics. In W. S. Hoar, D. J. Randall, J. R. Brett (eds.) Fish physiology. Academic Press, New York.

ALLENDORF, F. W., MITCHELL, N.. RYMAN, N. AND STẢHL. G. 1976. Genetic variation in Scandinavian brown trout (Salmo trutta L.); evidence of distinct sympatric population. Hereditas, 83, 73-82.

AVISE, J. C. 1974. Systematic value of electrophoretic data. Syst. Zool., 23, 465-481.

AVISE, J. C., PATTON, J. C. AND AQUADRO, C. F. 1980 . Evolutionary genetics of birds. II. Conservative protein evolution in North American sparrows and relatives. Syst. Zool., 29, 323-334.

BACCUS, R., RYMAN, N.. SMITH. M. H.. REUTERWALl, C. AND CAMERON, D. Genetic variability and differentiation of large grazing mammals. J. Mamm., 64, 109-120.

BERGMANN, F. 1976. Beiträge zur Kenntnis der Inf rastrukturen beim Rotwild. Teil II. Erste Versuche zur Klärung der genetischen Struktur von Rotwild-populationen an Hand von Serumprotein-Polymorphismen. Z. Jagdwiss., 22, 28-35.

CAMERON, A. G. 1923. The wild red deer of Scotland. Edinburgh and London.

CHAKRABORTY, R., FUERST, P. A. AND NEI, M. 1980. Statistical studies on protein polymorphism in natural populations. III. Distribution of allele frequencies and the number of alleles per locus. Genetics, 94, 1039-1064.

CHAKRABORTY, R., HAAG, M., RYMAN, N. AND STÅHL, G. 1982. Hierarchical gene diversity analysis and its application to brown trout population data. Hereditas, 97, 17-21.

CLAYTON, J. W. AND TRETIAK, D. N. 1972. Amine-citrate buffers for $p \mathrm{H}$ control in starch gel electrophoresis. J. Fish. Res. Board. Can., 29, 1169-1172.

CORBET, G. B. 1978. The mammals of the palaearctic region. A taxonomic review. British Museum (Natural History), Cornell University.

CORBIN, K. W. 1977. Genetic diversity in avian populations. In S. A. Temple (ed.) Endangered birds, Management Techniques for Preserving Threatened Species. University of Wisconsin Press.

DARNALl, D. W. AND KLOTZ, I. M. 1975. Subunit constitution of proteins: A Table. Ach. Biocheml Biophys., 166, 651-682.

EKMAN, H. 1979. Kronhjorten i Sverige-en faktasammanstälning. Arbetsunderlag för jakt och viltvairdsberedningen. $17 \mathrm{p}$. (In Swedish).

ELLERMAN, J. R. AND MORRISON-SCOTT, T. C. 1966. Checklist of Palaearctic and Indian mammals 1758 to 1946 . London. 
FALCONER, D. S. 1960. Introduction to quantitative genetics. Oliver and Boyd, Edinburgh and London.

FR ANKEL, O. H. AND SOULÉ, M. E. 1981. Conservation and evolution. Cambridge University Press.

GYLLENSTEN, U. 1980. Agarose gel electrophoresis-An alternate method of analyzing protein polymorphisms in serum. Report 4. Dept. of Genetics, University of Stockholm.

GYLLENSTEN, U. AND RYMAN, N. The population structure of marine and freshwater fish: Differences in the geographic distribution of biochemical genetic variation (in preparation).

GYLLENSTEN, U. Isozyme loci and a comparison of the amount and distribution of genetic variability in Scandinavian populations of willow grouse (Lagopus lagopus L.) and rock ptarmigan (Lagopus mutus L.) (in preparation).

GYLLENSTEN, U., REUTERWALL, C., RYMAN, N. AND STÄHL, G. 1980. Geographical variation of transferrin allele frequencies in three deer species from Scandinavia. Hereditas, 92, 237-241.

HARRIS, H. AND HOPKINSON, D. A. 1976. Handbook of enzyme electrophoresis in human genetics. North-Holland, Amsterdam.

KINCAID, H. L. 1976. Inbreeding in rainbow trout (Salmo gairdneri). J. Fish. Res. Board. Can., 33, 2420-2426.

LOWE, V. P. W. AND GARDINER, A. S. 1974. A re-examination of the subspecies of red deer (Cervus elaphus) with particular reference to the stocks in Britain. J. Zool., Lond., 174, 185-201.

LÖNNBERG, E. 1906. On the geographical races of the red deer in Scandinavia. Ark. Zool., Stockh., 3, 1-19.

MANLOVE, M. N., AVISE, J. C., HILLESTAD, H. O., RAMSEY, P. R., SMITH, M. H. AND STRANEY, D. O. 1975. Starch gel electrophoresis for the study of population genetics in white-tailed deer. In W. A. Rogers (ed.) Proc. 29th Ann. Conf. S.E. Assoc, Game and Fish Comm. Oct. 12-15.

McDOUGALL, E. I. AND LOWE, V. P. W. 1968. Transferrin polymorphism and serum proteins of some British deer. J. Zool, Lond., 155, 131-140.

NEI, M. 1972. Genetic distance between populations. Amer. Nat., 106, 283-292.

NEI, M. 1975. Molecular population genetics and evolution. North-Holland, Amsterdam.

NEI, M., MARUYAMA, T. AND CHAKRABORTY, R. 1975. The bottleneck effect and genetic variability in populations. Evolution, 29, 1-10.

NEVO, E. 1978. Genetic variation in natural populations; patterns and theory. Theor. Pop. Biol., 13, 121-177.

RALLS, K., BRUGGER, K. AND BALLOU, J., 1979. Inbreeding and juvenile mortality in small populations of ungulates. Science, 206, 1101-1103.

REUTERWALL, C. 1980. Genetic variability in a large game species, the moose (Alces alces): Patterns of differentiation and some management implications. Ph.D. dissert., University of Stockholm.

RIDGWAY, G. J., SHERBURNE, S. W. AND LEWIS, R. D. 1970. Polymorphisms in esterases of Atlantic herring. Trans. Am. Fisheries Soc., 99, 147-151.

RYMAN, N. AND STÅHL, G. 1980. Genetic changes in hatchery stocks of brown trout (Salmo trutta). Can. J. Fish. Aquat. Sci, 37, 82-87.

RYMAN, N., REUTERWALL, C., NYGRÉN, K. AND NYGRÉN, T. 1980a. Genetic variation and differentiation in Scandinavian moose (Alces alces). Are large mammals monomorphic? Evolution, 34, 1037-1049.

RYMAN, N., BACCUS, R., REUTERWALL, C. AND SMITH, M. H. 1980b. Effective population size, generation interval, and potential loss of genetic variability in game species under different hunting regimes. Oikos, 36, 257-266.

RYMAN, N., BECKMAN, G., BRUUN-PETERSEN, G. AND REUTERWALL, C. 1977. Variability of red cell enz'jmes and genetic implications of management policies in Scandinavian moose (Alces alces). Hereditas, 85, 157-162.

RYMAN, N., CHAKRABORTY, R. AND NEI, M. 1983. Differences in the relative distribution of human gene diversity between electrophoretic and red and white cell antigen loci. Hum. Hered., 33, 93-102.

SELANDER, R. K. AND KAUFMAN, D. W. 1973. Genic variability and strategies of adaptation in animals. Proc. Natl. Acad. Sci., 70, 1875-1877.

SENNER, J. W. 1980. Inbreeding depression and the survival of zoo populations. In M. E. Soulé and B. A. Wilcox (eds.) Conservation biology-An evolutionary ecological perspective. Sinauer Associates, inc.

SMITH, R. H. 1979. On selection for inbreeding in polygynous animals. Heredity, 43, 205-211. 
SNEATH, P. H. A. AND SOKAL, R. R. 1973. Numerical taxonomy. W. H. Freeman and Co., San Francisco.

SOKAL, R. R. AND ROHLF, F. J. 1969. Biometry, W. H. Freeman and Co., San Francisco. SOULÉ, M. E. AND WILCOX, B. A. (eds.) 1980. Conservation biology-An evolutionary ecological perspective. Sinauer Associates, Stamford, Conn.

WhitehEAD, G. K. 1978. Threatened deer. IUCN Publ., Switzerland. 